\title{
A Large-Scale Test of Gender Bias in the Media
}

\author{
Eran Shor, ${ }^{a}$ Arnout van de Rijt, ${ }^{b}$ Babak Fotouhic
}

a) McGill University; b) Utrecht University; c) Harvard University

Abstract: A large body of studies demonstrates that women continue to receive less media coverage than men do. Some attribute this difference to gender bias in media reporting-a systematic inclination toward male subjects. We propose that in order to establish the presence of media bias, one has to demonstrate that the news coverage of men is disproportional even after accounting for occupational inequalities and differences in public interest. We examine the coverage of more than 20,000 successful women and men from various social and occupational domains in more than 2,000 news sources as well as web searches for these individuals as a behavioral measure of interest. We find that when compared with similar-aged men from the same occupational strata, women enjoy greater public interest yet receive less media coverage.

Keywords: gender; bias; media coverage; computational analysis

Citation: Shor, Eran, Arnout van de Rijt, and Babak Fotouhi. 2019. "A Large-Scale Test of Gender Bias in the Media." Sociological Science 6: 526-550.

Received: June 6, 2019

Accepted: June 13, 2019

Published: September 3, 2019

Editor(s): Jesper Sørensen, Olav Sorenson

Dol: $10.15195 / \mathrm{v} 6 . \mathrm{a} 20$

Copyright: (C) 2019 The Author(s). This open-access article has been published under a Creative Commons Attribution License, which allows unrestricted use, distribution and reproduction, in any form, as long as the original author and source have been credited. (C) (i)
$\mathrm{M}$ EDIA attention is crucial for individuals in various social and occupational domains and can have substantial consequences for their success, and even their well-being (Hooghe, Jacobs, and Claes 2015; Solomon, Soltes, and Sosyura 2014; Sorensen 2007). Recent studies analyzing large-scale newspaper data sets suggest that the rise in the share of newspaper coverage focusing on women has recently almost grounded to a halt (Gallagher 2010; Macharia 2015). The ratio of women to men in newspaper articles has stabilized around 1:4 (Macharia 2015; Shor et al. 2014b, 2015), whereas the ratio for face images ranges from 1:1.5 to 1:4 (Jia et al. 2016). We have previously shown (Shor et al. 2015; Shor, van de Rijt, and Miltsov 2019) that these persistent differences are not primarily the result of gender differences in the newsroom. When women replace men as newspaper editors or when women reach other key positions in newsrooms, this does not substantially improve women's volume of coverage. However, it remains possible that all reporters and editors, regardless of gender, subscribe to hegemonic masculine cultural ideologies that give preference to men, their interests, and their actions more than those of women (Ridgeway 2013; Ross 2009).

Do mainstream media have a coverage bias against women? The answer to this longstanding question is not at all straightforward. Scholars have used the term bias quite liberally when speaking about inequalities in the media coverage of men and women in various social and occupational domains (e.g., Cooky, Messner, and Hextrum 2013; Davis 1982; Eastman and Billings 2000; Falk 2010). In most of these studies, "bias" is used to indicate newsmakers' tendency to write and publish more stories featuring men. However, although a long line of research has unequivocally demonstrated that women are much less likely to appear in various media than men are (see most recently Jia et al. [2016] and Macharia [2015]), we argue that this in itself does not provide sufficient evidence that coverage of men is disproportionate. At least two alternative explanations must be considered. 
The first alternative explanation for gender differences in news coverage is occupational inequalities. Studies have repeatedly shown the dominant presence of men in various social and employment categories. Men are more likely both to enter occupations and social domains that receive greater media attention and to hold the most senior, powerful, and prestigious positions in these domains (England $2005,2010)$. It naturally follows that mainstream media report more on men than on women. In order to claim that the media have a quantitative coverage bias against women, one must first demonstrate that women remain less likely to garner media attention when compared with men with similarly prominent positions and achievements.

Second, inequalities in coverage might reflect disproportionate public interest in men. This may be because of audiences' preferences for news about men or because men may generate greater interest by engaging in behaviors the public finds more newsworthy. For example, it may be that the average male presidential candidate produces more surprising or outrageous comments and scandals on a daily basis, leading audiences to be more interested in reading about these statements and occurrences. Whatever the reason for differential interest, media organizations and newsmakers may simply tailor to it without having a clear preference of their own. Hence, in order to claim that media are biased against the coverage of women, one would have to show not only that the average woman receives fewer mentions but also that the public is not more interested in her male colleague.

In the current article, we assess whether mainstream media indeed show an inclination toward the coverage of men even when accounting for equivalent structural positions and for public interest. We seek to address the following three research questions: (1) Do women receive less coverage than men even when they have reached equivalent positions or achievements in politics, the business world, entertainment, sports, and other social and occupational spheres? (2) Does public interest in men and women who have reached such similar positions differ? And (3) do women receive less media attention than comparable men even after taking into account both their structural positioning and the public interest they attract?

\section{Why Might Successful Women Receive Less Coverage Compared With Successful Men? Causal Mechanisms and Research Hypotheses}

Below, we consider three major approaches to explaining gender inequalities in coverage. Our discussion is informed by insights from the literatures on workforce inequalities and gender pay gaps. We maintain that inequalities in the media coverage of men and women may be attributed primarily to one of three major classes of explanations: (1) real-world structural inequalities, (2) unequal public interest, and (3) media-related inequalities, such as newsmaker predispositions and unequal access/response to reporters. 


\section{Structural Inequalities in the Workforce and in High-Profile Positions}

One potentially powerful explanation for women's coverage volume disadvantage is that men are more likely to (1) enter occupations and domains that receive greater media attention and (2) hold the most senior, powerful, and prestigious positions in these domains.

Research by sociologists and economists on labor market segmentation (Leicht 2008) highlights the differential entry of women and men into fields such as politics, business, the security forces, and other high-profile professions and fields (e.g., movie directors, musical producers, and songwriters in the entertainment industry). This literature highlights barriers such as direct discrimination in hiring decisions by employers (England 1992), differential recruitment practices often relying on personal gendered networks (Fernandez and Sosa 2005; Folke and Rickne 2016; Morgan 1998), and powerful cultural stereotypes about the types of jobs that women are able or unable to perform or master (England 2010; England and Li 2006; Reskin 2003; Reskin and Bielby 2005). Scholars have also highlighted cultural beliefs and educational ideologies, which operate to direct women into the domestic sphere or into professions with lower visibility and pay (Correll 2004). As a result, women are often channeled or select themselves into social and occupational spheres that, according to most journalistic standards, are less newsworthy (England 2005; England and Li 2006)

Within jobs, numerous studies have demonstrated that women often face a "glass ceiling," where their progress in the workforce, in politics, and in other professional and public domains is hindered by persistent institutional structures and cultural ideologies (Cotter et al. 2001; Folke and Rickne 2016; Kay and Hagan 1995; Ridgeway 2011). This glass ceiling becomes increasingly rigid and impermeable the higher up women move in a given hierarchy (Marx Feree and Purkayastha 2000). To illustrate, although women have been increasingly successful at attaining political positions in the United States, the large majority of the most senior political positions (such as presidents, senators, Army generals, and Supreme Court justices) are still occupied by men.

Given the strength and persistence of glass ceiling effects in various domains, one might argue that journalists have no choice but to report on men more than they do on women if they are to cover those events that involve successful politicians, businesspeople, and entertainers. Much of the advantage in coverage volume that men enjoy in the media may thus be ascribed to real-world structural inequalities that disadvantage women. However, it remains unclear whether such real-world inequalities, by themselves, are powerful enough to account for the entire difference in the coverage volume of men and women. One way to begin examining this is to compare only women and men who hold specific equivalent structural positions or achievements, in particular, high-profile positions such as state senators (politics), company founders (business), Oscar winners (entertainment), and Olympic medal winners (sports). If men still hold a coverage advantage even when compared with women in equivalent occupations and similar achievements, then coverage differentials are not entirely due to structural inequalities. 
Hypothesis 1: Women receive less media coverage than men do within the same occupations and structural positions.

\section{Inequalities in Public Interest and Newsworthiness for Equivalent Positions}

We next propose that even a systematic comparison of men and women who have reached equivalent positions in various social and occupational subdomains remains insufficient, as it is also important to account for public interest. Popular media outlets do not operate in a vacuum; they need to consider readership and viewership ratings and they face commercial concerns and constraints. Journalists and editors often ask themselves whether a given individual is of sufficient public interest to merit coverage; that is, to what extent are readers and viewers interested in knowing more about this individual? We may therefore ask: are there systematic differences in public interest between men and women with equivalent notable positions?

The literature on gender inequalities, particularly in the workplace, offers a number of mechanisms through which gender may interact with public interest and shape it. On the one hand, one might argue that women who have succeeded in reaching high-end social and professional positions might attract more interest when compared with their male counterparts. First, these women are simply rarer and therefore might be perceived as more "exotic," making for an interesting journalistic story. Second, it may be that the women themselves had to be more talented, ambitious, and hardworking than men in order for them to overcome institutional barriers. For example, Folke and Rickne (2016) argue that given the stringent selection and promotion processes that women face in politics, those women who remain in the pool of potential candidates for promotion are likely to be more qualified than their male counterparts. Supporting this premise, recent research suggests that those women who make it into leading executive positions in the business world offer unique advantages to their firms, including an improvement in firm performance (Khan and Vieito 2013; Weber and Zulehner 2010). In other words, those women who manage to reach high-level occupational positions in the face of well-documented barriers and discrimination are likely to be exceptionally talented individuals. They often possess remarkable skills and charisma, which, in turn, might make them particularly newsworthy.

On the other hand, a long tradition of feminist and gender theory suggests that women might in fact attract less public interest even when they do reach leading social and professional positions. Some scholars (Fiske 2011; Lamont 2012; Ridgeway 2013; Ridgeway et al. 2009) have emphasized the role of status and cultural beliefs in maintaining gender and racial inequalities. Entrenched cultural beliefs about social categories and the types of individuals who deserve special respect shape people's expectations of themselves and of others. Groups that enjoy greater resources to begin with (e.g., men and whites) are perceived as better-more capable, competent, and interesting. As these beliefs are shared by dominants and subdominants alike, they institutionalize and become both legitimate and prevalent. Gender status beliefs advantage men simply because they are men, not because 
they have more merit, resources, or power. They thus give men an advantage over women in similar positions who are just as talented, successful, or powerful. These men are perceived as more competent, interesting, and worthy of both their positions and public attention.

The literature on labor inequalities and pay gaps further provides a set of mechanisms for explaining gendered differences in public interest. These mechanisms all suggest that women remain of lesser public interest even when reaching high-end positions in the business world, in politics, and in arts, sports, and entertainment. Among them are (1) differential assignments to internal positions and tasks, (2) potentially shorter careers or durations of occupying prominent offices, and (3) culturally influenced styles of communication and self-promotion. We explore these mechanisms below.

In terms of differential assignment, a body of literature suggests that women and men are differentially slotted into positions and tasks within organizations. Women tend to receive inferior work assignments, which are less challenging and complex and entail less authority and work responsibilities and lower visibility (Madden 2012; Kanter 1977; Kay 1998; Reskin and Bielby 2005; Smith 2002). Even when women do enter prestigious professions or reach high-end positions in these professions, they often have shorter career spans. Women and minorities are more likely to be promoted to precarious leadership positions, with higher turnover rates and professional instability, a phenomenon that some have referred to as a "glass cliff" (Cook and Glass 2013; Ryan and Haslam 2005). Consequently, the time women spend in publicly visible offices, which attract media attention, is shorter relative to that of their male counterparts who have reached a similar office. Women are also more likely to take parental leaves and work part-time and flexible hours in order to spend more time with their families (Budig and England 2001; Glass and Camarigg 1992; Sanchez and Thomson 1997). This hurts their hiring and promotion chances but also takes them away for extended periods from positions that are in the public eye and attract media attention.

Finally, some scholars have suggested that even those women who reach highend positions may be less competitive, ambitious, confident, assertive, or selfpromoting when compared with similarly positioned men (Castagnetti and Rosti 2013; Fox and Lawless 2014; Manning and Saidi 2010). Years of gendered socialization and prevailing gendered social norms and status beliefs have taught women to remain modest and refrain from bragging about their achievements or deliberately putting themselves in the limelight. Consequently, even when women do reach elite social and occupational positions, they are more likely to maintain their privacy and are reluctant to put themselves forward and actively seek public attention. Without extensive self-promotion, the public is likely to judge these women as less interesting and worthy of attention (Ridgeway 2013). This final mechanism is especially relevant to social and occupational fields such as the arts, entertainment, and athletics, where organizational hierarchies and inequalities might play a lesser role in determining public interest.

Taken together, these various mechanisms suggest that even when women do reach high-end structural positions they may still be considered less interesting than men who have reached similar positions. We therefore propose the following: 
Hypothesis 2: Women attract less public interest than men do within the same occupations and structural positions.

\section{Media-Related Factors: Bias and Discrimination in Media Coverage}

The literature on gendered pay gaps often concludes that when these gaps persist after accounting for work profiles, opportunity structures, and human capital, they may be understood as resulting from wage discrimination (Castagnetti and Rosti 2013; Dinovitzer, Reichman, and Sterling 2009). That is, any difference not due to productivity-relevant personal attributes may be considered as due to bias. We wish to extend this logic to gendered media inequalities and suggest that those differences that cannot be ascribed to either structural inequalities or differences in public interest can reasonably be understood as gender bias.

As is the case with biases in public interest, media coverage bias might either favor or disfavor women. On the one hand, journalists and editors may practice tokenism, celebrating the success of women and seeking to show that women can really make it and provide future role models for young girls. Consequently, journalists may actively seek stories on women who made it to the top and write about them. Others may want to highlight women's successes and accomplishments simply in order to prove that they are not biased against women. Journalists and editors are frequently sensitive to criticisms from academics and the public regarding the status of women in the media and may be motivated to show that they promote women's coverage whenever possible.

On the other hand, literature on gender inequalities, which we reviewed in the previous section, is also relevant to understanding the media's treatment of women. In particular, Ridgeway $(2011,2013)$, Ridgeway and Correll (2004), and Ridgeway et al. (2009) argue that status biases affect individuals' willingness to pay attention to women and positively evaluate their actions, words, efforts, and accomplishments: "The same idea 'sounds better' coming from the advantaged than from the disadvantaged" (Ridgeway 2013:6). As processes of status entrenchment accumulate and hierarchies of influence and prominence become binding social structures, men are "revealed to be simply 'better' at valued social tasks than are women" (Ridgeway 2013:6). Ridgeway further argues that we are rarely aware of how we are all implicit in the production of gender statuses. We habitually make judgments about who is better and more deserving of resources and attention without consciously thinking about these judgments or acknowledging them.

Mass communication scholars make similar arguments, maintaining that the differential media coverage of women and men is not merely a reflection of existing gender inequities in the public sphere or differential public interest. Rather, media practices significantly exacerbate and artificially magnify these inequalities (De Swert and Hooghe 2010; Tuchman 1979). The daily choices of journalists, editors, and publishers working in a masculine cultural environment contribute to the aggravation of coverage imbalances and skew coverage patterns in favor of men. Consequently, even women who do manage to reach high-level positions often fail to receive the same degree of coverage as their male counterparts. The historical dominance of men in editorial positions has created a power structure, dictating 
masculine coverage and editorial norms, which favor issues associated with men, their actions, and their preferences, while at the same time treating these norms as objective professional routines (Mills 1997; Rodgers and Thorson 2003; Ross and Carter 2011).

Anecdotal evidence suggests that women may indeed receive reduced media attention when compared with men even when they do reach positions of power and prestige. Most of the previous relevant research has focused on the fields of politics and sports. In politics, studies that analyzed the coverage of women running for office in the United States reported mixed results. Falk (2010), who followed nine presidential campaigns, reported that women received consistently less campaign coverage and issue attention than their male counterparts. Similarly, Heldman, Carroll, and Olson (2005), who examined Elizabeth Dole's presidential campaign, reported that she did not receive an amount of media coverage consistent with her standing as the number two candidate in the polls. Other studies, however, failed to confirm these tendencies. Studies on mayoral candidates (Atkeson and Krebs 2008), candidates for the House of Representatives (Lavery 2013), and candidates for state senators or governors (Smith 1997) found no substantial differences between the coverage volume of male and female candidates. Other recent studies have even reported that women running for senatorial, gubernatorial, and vice presidential offices in the 2000s received more coverage when compared with their male corunners (Robertson et al. 2009; Wasburn and Wasburn 2011). Conversely, in the most extensive and carefully controlled analysis to date, Hooghe et al. (2015) examined the television coverage of 493 Belgian members of parliament (MPs). They found that even after controlling for members' age and specific political position (men tend to hold more senior positions), female MPs were significantly less likely to be allotted speaking time in news broadcasts.

Sports is a relatively unique field, as male and female sports are segregated at both the amateur and the professional levels. Thus, a comparison of similarly equivalent positions is somewhat more challenging. Still, research on coverage differentials between female and male sports and athletes found that between 90 percent and 95 percent of all articles in various media were on male athletes or men's sports (Cooky et al. 2013). Yet, we are unaware of any systematic large-scale analyses that compared the coverage volume for a large number of men and women with a similar status or with similar achievements (e.g., Olympic gold medalists or winners of tennis Grand Slam competitions).

Although the studies reviewed above are informative and instructive, they share a number of shortcomings, which are addressed by the present study. First, most of them have examined the coverage in a single domain (e.g., sports), relying on a small sample of individuals and media outlets. Such research designs render generalizations problematic and increase the risk for anecdotal and subjective evaluations. Second, these studies did not empirically substantiate the common conclusion about gender coverage bias in the media. This term is employed quite loosely when talking about gender differences in media coverage (Cooky et al. 2013; Davis 1982; Eastman and Billings 2000; Falk 2010) but mostly without evidence for a clear preference for men over women who have reached similar positions and achievements. Finally, as we argue above, it is not enough to simply compare the 
volume of coverage for women and men who have reached equivalent positions or achievements. To begin demonstrating media bias, one has to, at the very least, also account for public interest and show that the media fail to cater to what media consumers wish to read or hear about (even while recognizing that these interests themselves are socially constructed). In other words, the mere existence of coverage inequalities among individuals from different social groups does not constitute evidence for media bias because it may be justified by journalistic professional standards and/or by commercial considerations. In the current study, we will therefore examine media inequalities in coverage (supply) while accounting for both structural inequalities and public interest (demand). That is, we test the following proposition:

Hypothesis 3: When compared with men who (1) have reached the same achievements or occupational positions and (2) draw similar public interest, women receive less media coverage.

\section{Sampling, Data, and Measurements}

\section{Sampling Individual Names by Domain}

In order to obtain a large and systematic sample of names, we collected data from Wikipedia category databases (see https://en.wikipedia.org/wiki/Wikipedia:Categorization). We first constructed an initial list of larger social and occupational domains based on common newspaper categorizations. These include politics, business, entertainment, sports, and arts/literature. We then devised a sublist of prominent subdomains within each of these larger domains. For example, within the domain of entertainment, we outlined the following subcategories: actors (TV and film), directors, singers, and dancers. In some domains, we also identified more specific subcategories, ones in which individuals are particularly likely to attract media attention (e.g., Oscar nominees or Pulitzer Prize winners).

We next turned to the Wikipedia category database, which includes extensive lists of both female and male individuals in most of the domains and subdomains that we preidentified. For example, to assemble our list of singers, we extracted all 1,535 names appearing under the category "American female singers" and all 2,046 names appearing under the category "American male singers." In some cases, there was no specific category for men (e.g., for chief executives). In such cases, we extracted all the names from the general category (e.g., "American chief executives") and then eliminated from the list names that already appeared on the specific category for women ("American women chief executives"). We next manually validated that the remaining names all belonged to men. Although the Wikipedia lists were not (and could not be) complete for most categories (e.g., singers), they were complete for others, such as U.S. senators, Oscar nominees, billionaires, and tennis Grand Slam winners. Moreover, even when the lists were incomplete, they were mostly extensive and included the majority of the wellknown men and women in each subdomain.

Altogether, we assembled an initial database containing the names of 26,281 men and 12,372 women. Seeking to account for potential imbalances between the 
ways that lists of men and women were collected in each domain and subdomain, we then constructed a smaller matched-pairs balanced data set by applying the following matching rules. First, as our coverage data come from the first decade of the new millennium, we eliminated all names of individuals born prior to 1920, as these were much less likely to appear in recent news. This truncation of data is also justified given the sharp imbalance between women and men born before 1920 in our various domains. Many of the subdomains included no women born prior to that year.

Second, because almost all the Wikipedia categories included more male names than female names, we paired each woman with a man from her specific subdomain (e.g., a female U.S. senator with a male U.S. senator) using their year of birth. When there was more than one same-aged man, we calculated the median of Wikipedia page views among these men during the period for which we have media coverage data and then selected one man whose page views numbers were the closest to this median value. We allowed for no more than a 10-year difference between a man and a woman in each of the matched pairs. Applying this matching rationale attends to imbalances in times of activity and public visibility. The average age of men in our preliminary sample was higher than that of women, as most women only entered various social and occupational fields in later years. For example, although professional male basketball in the United States has existed since the 1940s, a professional female league was only established in 1996. Such differences skew assessments of relative coverage, as older individuals in fields like sports, entertainment, or the arts were more likely to be retired and less likely to be active by the first decade of the new millennium. In our final matched sample, 99.8 percent of the pairs have an age difference of two years of less, and the maximum age difference is four years.

Finally, in our concluding analysis, we sought to account for public interest, as previous research has shown that women may need greater levels of public interest to be included in Wikipedia (Skiena and Ward 2013). We therefore paired each woman with a man from the same subdomain who (1) was no more than 10 years apart from that woman (e.g., Susan Collins was born in 1952; Lindsey Graham was born in 1955) and (2) who had the closest number of Wikipedia page views in the period 2004 to 2009, for which we have daily media coverage data ${ }^{1}$ (e.g., Senator Susan Collins, who had a median number of 9,203.5 monthly page views was matched with Senator Lindsey Graham, who had a median number of 9,313 page views). To maximize comparability, whenever we could not find a match with no more than a 10-year age difference and no more than a 10 percent difference in page views, we omitted the pairing in question from the final analysis. In Appendix 1 of our online supplement, we present the full list of matched pairs for the subcategory of senators. Appendix 1 of the online supplement shows that in almost all cases we were able to reach very good matches, both in terms of Wikipedia page views (typically, no more than a 2 percent difference in number of views) and in terms of age (typically, no more than a five-year age difference).

Overall, we were able to successfully pair 10,470 women with 10,470 men for a total sample of 20,940 individuals appearing in the Wikipedia categories. Table 1 
details the full distribution and the number of matched pairs in each field and subfield.

\section{Media Coverage}

Our measure of media coverage relies on data collected by the Lydia news analysis system (Bautin et al. 2010; Shor et al. 2014a; van de Rijt et al. 2013). Lydia provides time-stamped records of occurrences of person names in the scanned and digital records of more than 2,000 newspapers, magazines, and online news sources (most of them American) between 2004 and 2009, after which most online newspapers placed most of their content behind paywalls. This timeframe offered a unique opportunity to access unprecedented amounts of data from a very large and highly diverse number of news sources. These sources include both large national newspapers and smaller local ones as well as weekly magazines and online websites of major TV news stations and several prominent news websites, portals, and blogs.

One possible challenge to the validity of our analysis is common names. Our count of newspapers' mentions is unable to distinguish between two individuals with the same name. This problem would be particularly salient if common names were not evenly distributed among men and women (which is certainly possible). To tackle this problem of common names, we excluded from the analyses presented in this article all names that appeared in the Wikipedia categories followed by parentheses. Most often, such parentheses are used for individuals with a common name, where Wikipedia contains multiple web pages, one for each of these individuals. For example, the name "Daniel Levy" has six different Wikipedia pages, each marked with a parenthesis after the name that notes the individuals' profession or affiliation: politician, businessman, political analyst, TV personality, classical pianist, and sociologist (not a co-author).

\section{Public Interest}

We argue that attempting to measure media bias by comparing apparently equivalent social and structural positions is insufficient. Such a strategy fails to fully capture the role of personal charisma, individual achievements, gendered cultural norms about self-promotion, and gendered differential public interest within domains. As these traits are not randomly distributed between men and women, accounting for public interest becomes a crucial step in trying to assess gendered media bias. In Appendix 2 of the online supplement, we demonstrate the importance of accounting for public interest and the dangers involved in ignoring it.

Wikipedia page views ("hits") as a measure of public interest. Search engine queries on computers and smartphones are a dominant expression of public interest. When people are interested in and wish to know more about a politician, artist, or businessperson, they type his or her name in a search engine. This makes name queries a promising measure of public interest. Unfortunately, most major search engines restrict access to longitudinal records of search queries, making it impossible to obtain such quantities for large volumes of names within a reasonable amount of time. However, when querying names of well-known individuals, their Wikipedia page 
Table 1: News coverage: article mentions of age-matched women and men in selected categories (yearly medians, 2004-2009).

\begin{tabular}{|c|c|c|c|c|c|}
\hline \multirow[t]{2}{*}{ Category } & \multirow[t]{2}{*}{ Subcategory } & \multirow[t]{2}{*}{$\begin{array}{r}\text { Number of } \\
\text { matched } \\
\text { pairs }\end{array}$} & \multicolumn{2}{|c|}{$\begin{array}{l}\text { Coverage: median } \\
\text { number of } \\
\text { newspaper } \\
\text { mentions per year }\end{array}$} & \multirow[t]{2}{*}{$\begin{array}{l}\text { Relative coverage } \\
\text { (women vs. men) } \\
\text { and bootstrap tests } \\
\text { of difference ( } 95 \% \\
\text { confidence intervals) }\end{array}$} \\
\hline & & & Women & Men & \\
\hline All categories & All names & 10,470 & 301 & 385 & $0.78(0.73-0.83)^{\dagger}$ \\
\hline \multirow[t]{11}{*}{ Entertainment (U.S.) } & All entertainers & 5,904 & 265 & 386 & $0.69(0.64-0.75)^{\dagger}$ \\
\hline & Film actors & 3,908 & 301 & 432 & $0.70(0.62-0.78)^{\dagger}$ \\
\hline & Television actors & 3,916 & 281 & 391 & $0.72(0.64-0.79)^{\dagger}$ \\
\hline & Film directors & 233 & 705 & 617 & $1.14(0.78-1.92)$ \\
\hline & Singers & 1,097 & 325 & 578 & $0.56(0.47-0.68)^{\dagger}$ \\
\hline & Pop singers & 219 & 2,697 & 952 & $2.83(1.92-4.64)^{\dagger}$ \\
\hline & Dancers & 169 & 1,042 & 454 & $2.30(1.35-3.37)^{\dagger}$ \\
\hline & Television personalities & 353 & 577 & 717 & $0.80(0.56-1.15)$ \\
\hline & Radio personalities & 103 & 232 & 385 & $0.60(0.35-1.08)$ \\
\hline & Oscar nominees & 230 & 10,393 & 17,547 & $0.59(0.44-0.78)^{\dagger}$ \\
\hline & Emmy nominees & 145 & 3,331 & 6,751 & $0.49(0.36-0.82)$ \\
\hline \multirow[t]{8}{*}{ Politics (U.S.) } & All politicians & 828 & 531 & 2,635 & $0.20(0.16-0.25)^{\dagger}$ \\
\hline & Governors & 24 & 7,656 & 9,302 & $0.82(0.18-9.47)$ \\
\hline & Mayors & 112 & 761 & 757 & $1.01(0.62-1.84)$ \\
\hline & Cabinet secretaries & 21 & 8,825 & 23,392 & $0.38(0.06-1.58)$ \\
\hline & Presidential candidates & 41 & 1,385 & 23,634 & $0.06(0.01-0.19)^{\dagger}$ \\
\hline & Judges & 135 & 959 & 244 & $3.93(2.60-5.71)^{\dagger}$ \\
\hline & House representatives & 150 & 5,262 & 10,268 & $0.51(0.36-0.67)^{\dagger}$ \\
\hline & Senators & 30 & 37,344 & 48,696 & $0.77(0.34-1.13)$ \\
\hline \multirow[t]{5}{*}{ Business (U.S.) } & All businesspeople & 252 & 691 & 506 & 1.37 (0.87-2.07) \\
\hline & Chief executives & 99 & 870 & 622 & $1.40(0.61-2.34)$ \\
\hline & Business executives & 40 & 1,645 & 572 & $2.88(1.04-7.99)^{\dagger}$ \\
\hline & Company founders & 16 & 4,911 & 275 & $17.89(1.91-113.39)^{*}$ \\
\hline & Billionaires & 26 & 1,012 & 1,326 & $0.76(0.17-1.68)$ \\
\hline \multirow[t]{6}{*}{ Sports } & All athletes & 1,051 & 1,263 & 2,033 & $0.62(0.52-0.78)^{\dagger}$ \\
\hline & $\begin{array}{l}\text { Tennis Grand Slam champions } \\
\text { (all nations) }\end{array}$ & 59 & 6,807 & 5,186 & $1.31(0.46-3.72)$ \\
\hline & Soccer players (U.S.) & 121 & 339 & 2,551 & $0.13(0.08-0.17)^{\dagger}$ \\
\hline & Basketball players (U.S.) & 337 & 2,258 & 4,551 & $0.50(0.38-0.75)^{\dagger}$ \\
\hline & Golf players (U.S.) & 294 & 926 & 1,107 & $0.84(0.54-1.19)$ \\
\hline & Olympic athletes (U.S.) & 176 & 2,001 & 3,224 & $0.62(0.48-0.95)^{*}$ \\
\hline \multirow[t]{6}{*}{ Arts and literature } & All artists and writers & 1,392 & 232 & 225 & $1.03(0.85-1.17)$ \\
\hline & Painters & 158 & 71 & 49 & $1.46(0.78-2.35)$ \\
\hline & Photographers & 237 & 155 & 202 & $0.77(0.57-1.11)$ \\
\hline & Sculptors & 74 & 120 & 99 & $1.21(0.53-1.98)$ \\
\hline & Writers & 874 & 319 & 366 & $0.87(0.67-1.08)$ \\
\hline & Pulitzer Prize winners & 50 & 1,211 & 1,547 & $0.78(0.39-1.49)$ \\
\hline
\end{tabular}

${ }^{*} p<0.05,{ }^{+} p<0.01$ 
almost always comes up as one of the first-listed search results. Indeed, Yoshida et al. (2015) found that search figures obtained from Google Trends (a measure of how often a particular search term is entered into the Google search engine) correlated very strongly with Wikipedia page views $(r=0.92)$. Appendix 3 of the online supplement shows this relationship for the name "Anne Hathaway." Our own smaller-scale comparison of Google search results and Wikipedia page views revealed a similar resemblance. Unlike search queries, the frequencies of Wikipedia page views are publicly available, unrestricted, and free. Therefore, we use this measure as a powerful proxy for public interest in all names in our sample. ${ }^{2}$

Although the relative frequency of Wikipedia page views is by no means a flawless measure of public interest (we discuss some of its limitations below), it nevertheless provides several important advantages when assessing public interest and, consequently, media bias. First, by using this behavioral measure, we allow the public's revealed preferences to determine which figures are more interesting or newsworthy. Indeed, when looking only at more conventional measures of "importance," such as reaching a certain structural position (e.g., governor) or a tangible achievement (e.g., winning certain prizes or breaking an athletic record), one runs the danger of overemphasizing criteria that may have little to do with public preferences and tastes.

A second important advantage of using Wikipedia page views as a measure of interest is that it accounts, at least in part, for some of the unmeasured differences and inequalities between men and women, which we discussed in our review of the labor market and gender pay gap literature. Consider, for example, the proposition that women are often assigned roles and tasks of lesser importance and lower visibility in organizations. Whenever that is the case, we would expect these women to also draw lesser public interest, be queried for less in search engines, and be looked up on Wikipedia less frequently. Similarly, if women suffer from greater professional instability and turnover rates once they reach high-end positions, and consequently spend less time in the office compared with male colleagues, then this should be reflected in reduced public interest in these women once they exit the position. Finally, even the suggested differences in competitiveness and selfpromoting efforts between men and women should be reflected in our measure of interest. If women as a group are indeed less self-promoting and do not make egregious statements or highlight their abilities and achievements to the same degree as their male counterparts, then it may reasonably follow that the public would be less interested in them and would be less likely to search for their names in Wikipedia.

Finally, the Wikipedia page views measure exhibits both face validity and criterion validity. Scholars commonly agree that the number of web searches reflects the degree of public interest in the subject matter or individual (Nghiem et al. 2016; Ripberger 2011; Yoshida et al. 2015). According to Yoshida et al. (2015), at least for high-frequency keywords, Wikipedia page views serve as an effective resource for simulating web search trends and, consequently, public attentiveness and interest.

As a measure of public interest, Wikipedia page views also have some disadvantages. First, there is no complete overlap between those people who surf the Internet and newspapers' readership. For example, the former may tend to be younger, as 
they are likely to have computer and Internet skills, whereas a larger portion of the latter may be relatively older. Still, one may assume that both Wikipedia users and newspapers readers are relatively more educated (people who read) and that they are less likely to be poor, as indicated by their access to the Internet (to both Wikipedia and online newspapers) and/or their ability to subscribe to newspapers. In fact, we find no reason to assume that Wikipedia users and newspaper readers are two very different populations with very different tastes and interests. Furthermore, as we note above, we contend that Wikipedia queries are a good estimate of general public interest, regardless of the overlap between the populations of Internet users and newspaper readers.

A second drawback of Wikipedia page views, one that it shares with any other reasonable measure of public interest, is that it is informed by media coverage itself (Gans 1979; McCombs and Shaw 1972). Media coverage not only reflects but also shapes public interest. When newspapers and other media frequently mention certain individuals, media consumers would be more likely to search for these individuals online (including on Wikipedia). Indeed, the spike shown in Appendix 3 of the online supplement occurs on the day of a television broadcast on a movie in which Anne Hathaway played a major role. Conversely, journalists and editors are often sensitive to public interests and would be more likely to write about those individuals who receive higher online traffic (e.g., through name searches on various websites). It may even be that search engines are more likely to route users to Wikipedia pages of names that appear more prominently in mass media.

This partial codeterminacy of interest and coverage means that search queries and page views are measures of actual public interest, not of what public interest would have looked like in the absence of the agenda-setting effects of media coverage. This, in turn, means that its use leads to more conservative estimates of actual media coverage differentials. That is, because of the interdependency of various media, we might expect a strong correlation between the two measures. Therefore, our estimations of gendered coverage differentials in the news when controlling for Wikipedia page views are likely to be downwardly inclined. Hence, any residual discrepancy in favor of men (or in favor of women) should be interpreted as a conservative underestimate. There is an interesting parallel here with gender wage-gap measures, which are similarly conservative because they fail to account for profile differences between women and men generated by prior discrimination.

Finally, Internet users reach Wikipedia pages not only through direct searches but also through other means, such as by following links from other Wikipedia pages. These links may be organized in ways that give preference to certain groups of individuals. For example, it may be that when reading on a certain male basketball player, one is led to other male basketball players through hyperlinks, leading to greater traffic on those neighboring pages. To the extent that this trend systematically favors men, due to their overall higher presence on Wikipedia, we might therefore expect that our Wikipedia measure of interest will overestimate public interest in male figures. This would therefore also render estimates of gender coverage gaps downwardly biased.

Although cognizant of these potential shortcomings, we wish to reemphasize the very strong correlation between Wikipedia page views and Google search results, 
which gives us confidence that this is a powerful proxy of public interest, the only one readily available to researchers on such a large scale.

\section{Findings}

\section{Domain-Stratified Media Supply}

To test Hypothesis 1, we calculated ratios for the relative coverage of men and women in our sample. We first stratified the analyses by domain (e.g., entertainment, politics, and sports) and by subdomain (e.g., dancers or Olympians) so as to be able to compare men and women with equivalent structural positions or achievements and matched pairs of men and women by age. In Table 1, we present the number of matched pairs in each domain and subdomain (column 3), the median number of newspaper mentions for women and for men (columns 4 and 5, respectively), and the results (odds ratios) of permutation tests for gender differences in supply (column 6). The nonparametric bootstrap test ${ }^{3}$ assesses whether the difference in the median coverage of women and men is statistically significant. Note that because of the relatively small numbers of names in some of the subcategories, reported tests may suffer from low statistical power. ${ }^{4}$

The results presented in Table 1 provide substantial support for our first hypothesis, stating that women receive less media coverage compared with men who have reached similar achievements or structural positions. First, an examination of the entire set of matched pairs in our sample (representing 20,940 individuals in 10,470 matched pairs) reveals a large and statistically significant coverage advantage for men, with women receiving less than 80 percent of the coverage of men. This coverage disadvantage carries over to most of the specific categories and is especially salient in the fields of entertainment, politics, and sports. In entertainment, women receive substantially lower coverage overall and in subdomains. In politics, the difference in coverage is especially large, with men receiving five times greater coverage volume than women. There is one exception, with female judges receiving a larger share of news coverage than their male counterparts. In sports, successful female athletes receive about 60 percent of the coverage volume devoted to successful male athletes overall, and the difference is even larger in subcategories such as soccer and basketball.

Two fields in which differences were not statistically significant were business and arts/literature. The results for the business category are particularly interesting, as both female business executives and female company founders receive a substantially higher coverage volume (three to 18 times higher) than their male counterparts. It appears then, that this might be the one major category where our first hypothesis does not hold.

\section{Domain-Stratified Public Interest}

The analyses presented in Table 1 take an important step toward examining media bias by stratifying men and women according to social and occupational domains and accounting for notable achievements. Still, they fail to control for the degree to 
which the public is actually interested in a certain individual. In Table 2, we present the matched-pairs comparisons of the various subdomains but this time comparing public interest as measured by Wikipedia page views. Similarly to Table 1, we report the numbers of matched pairs in each domain and subdomain (column 3 ) as well as the monthly media number of visits to the Wikipedia pages of these women and men (columns 4 and 5) and bootstrap tests for the difference between these two figures (column 6).

Table 2 demonstrates that the median woman in our sample received more than 1.5 times more views of her Wikipedia page, suggesting greater overall public interest in these women. This result disconfirms our second hypothesis that men generate more public interest when compared with women in equivalent structural positions. Moreover, it suggests that women receive less media coverage despite enjoying greater public interest. This contrast between "supply" and "demand" presents strong evidence for gender bias. Had we found greater supply of and demand for men, then residual bias could be spurious, as a noisy measure of public demand would not fully account for gender differences. In the actual scenario, any measurement error in our measure of public interest renders our estimates conservative. That is, a more accurate measure would have provided even stronger estimates of net bias.

The tendency for women to enjoy greater public interest was not consistent across all categories. Women received more page views in all of the entertainment subcategories and in most subcategories in the field of business. Conversely, in politics and in sports, the median woman actually received a substantially lower number of page views. In politics, women received about one-third of the page views that men received, and in sports, women received less than half of the public interest, with categories such as female soccer and female basketball drawing particularly low relative interest.

\section{Domain-Stratified Media Supply, Accounting for Public Interest}

Trying to assess media coverage while accounting for both structural position and public interest, we conducted a matched-pairs analysis, matching individuals on subdomains, Wikipedia page views (interest), and age. Table 3 presents the results of this analysis. We examined the median number of Wikipedia page views for men and for women (columns 4 and 5), which, because of the matching, was nearly perfectly balanced in the various categories, and the median number of mentions for men and for women in each domain and subdomain (columns 6 and 7). We then used bootstrap and permutation tests to compute whether the relative coverage of women exceeded or fell short of the relative interest in women (column 8, on the right-hand side of the table).

Because Table 3 is quite dense, we present the main findings from the matchedpairs analysis (for all names and for each of the main domains) in Figure 1. The figure provides substantial support for our third hypothesis, showing that in all domains, except for sports, coverage for women was lower than that of similaraged men who reached equivalent structural positions and had a similar number of Wikipedia page views. The overall median number of mentions per year for a man 
Table 2: Public interest: Wikipedia page views for age-matched women and men in select categories (monthly medians, 2004-2009).

\begin{tabular}{|c|c|c|c|c|c|}
\hline \multirow[t]{2}{*}{ Category } & \multirow[t]{2}{*}{ Subcategory } & \multirow[t]{2}{*}{$\begin{array}{r}\text { Number of } \\
\text { matched } \\
\text { pairs }\end{array}$} & \multicolumn{2}{|c|}{$\begin{array}{c}\text { Interest: median } \\
\text { number of } \\
\text { Wikipedia page } \\
\text { views per month }\end{array}$} & \multirow[t]{2}{*}{$\begin{array}{l}\text { Relative coverage } \\
\text { (women vs. men) } \\
\text { and bootstrap tests } \\
\text { of difference ( } 95 \% \\
\text { confidence intervals) }\end{array}$} \\
\hline & & & Women & Men & \\
\hline All categories & All names & 10,470 & 1,083 & 690 & $1.57(1.498-1.647)^{\dagger}$ \\
\hline \multirow[t]{11}{*}{ Entertainment (U.S.) } & All entertainers & 5,904 & 2,539 & 2,053 & $1.24(1.16-1.33)^{\dagger}$ \\
\hline & Film actors & 3,908 & 3,731 & 3,147 & $1.19(1.09-1.29)^{\dagger}$ \\
\hline & TV actors & 3,916 & 3,510 & 3,007 & $1.17(1.08-1.27)^{\dagger}$ \\
\hline & Film directors & 233 & 1,291 & 837 & $1.54(1.03-1.96)^{\dagger}$ \\
\hline & Singers & 1,097 & 1,539 & 1,798 & $0.86(0.76-0.99)^{*}$ \\
\hline & Pop singers & 219 & 14,890 & 4,245 & $3.51(2.28-5.18)^{\dagger}$ \\
\hline & Dancers & 169 & 5,093 & 1,254 & $4.06(2.12-6.30)^{\dagger}$ \\
\hline & Television personalities & 353 & 2,852 & 1,750 & $1.63(1.08-2.04)^{\dagger}$ \\
\hline & Radio personalities & 103 & 1,223 & 658 & $1.86(1.11-2.70) *$ \\
\hline & Oscar nominees & 230 & 24,586 & 41,057 & $0.60(0.49-0.77)^{\dagger}$ \\
\hline & Emmy nominees & 145 & 14,207 & 19,221 & $0.74(0.65-1.02) *$ \\
\hline \multirow[t]{8}{*}{ Politics (U.S.) } & All politicians & 828 & 251 & 748 & $0.34(0.30-0.38)^{\dagger}$ \\
\hline & Governors & 24 & 1,894 & 1,436 & $1.32(0.65-3.81)$ \\
\hline & Mayors & 112 & 240 & 201 & $1.19(0.81-1.50)$ \\
\hline & Cabinet secretaries & 21 & 3,569 & 5,993 & $0.60(0.20-2.25)$ \\
\hline & Presidential candidates & 41 & 846 & 7,829 & $0.11(0.05-0.31)^{\dagger}$ \\
\hline & Judges & 135 & 234 & 151 & $1.55(1.19-2.25)^{\dagger}$ \\
\hline & House representatives & 150 & 1,320 & 1,192 & $1.11(1.02-1.25) *$ \\
\hline & Senators & 30 & 6,889 & 5,572 & $1.24(0.77-1.67)$ \\
\hline \multirow[t]{5}{*}{ Business (U.S.) } & All businesspeople & 252 & 995 & 607 & $1.64(1.32-2.11)^{\dagger}$ \\
\hline & Chief executives & 99 & 837 & 464 & $1.80(1.13-2.69) *$ \\
\hline & Business executives & 40 & 1,677 & 451 & $3.72(1.48-7.68)^{\dagger}$ \\
\hline & Company founders & 16 & 4,779 & 695 & $6.88(1.59-32.86)^{*}$ \\
\hline & Billionaires & 26 & 2,528 & 2,139 & $1.18(0.54-2.48)$ \\
\hline \multirow[t]{6}{*}{ Sports } & All athletes & 1,051 & 212 & 471 & $0.45(0.41-0.50)^{\dagger}$ \\
\hline & $\begin{array}{l}\text { Tennis Grand Slam champions } \\
\text { (all nations) }\end{array}$ & 59 & 3,126 & 4,388 & $0.71(0.36-1.85)$ \\
\hline & Soccer players (U.S.) & 121 & 94 & 953 & $0.10(0.05-0.15)^{\dagger}$ \\
\hline & Basketball players (U.S.) & 337 & 231 & 1,298 & $0.18(0.15-0.21)^{\dagger}$ \\
\hline & Golf players (U.S.) & 294 & 127 & 152 & $0.84(0.74-0.98)^{\dagger}$ \\
\hline & Olympic athletes (U.S.) & 176 & 490 & 475 & $1.03(0.65-1.28)$ \\
\hline \multirow[t]{6}{*}{ Arts and literature } & All artists and writers & 1,392 & 395 & 363 & $1.09(0.96-1.23)$ \\
\hline & Painters & 158 & 186 & 213 & $0.87(0.73-1.11)$ \\
\hline & Photographers & 237 & 354 & 289 & $1.22(0.91-1.50)$ \\
\hline & Sculptors & 74 & 169 & 138 & $1.22(0.89-1.99)$ \\
\hline & Writers & 874 & 524 & 509 & $1.03(0.86-1.26)$ \\
\hline & Pulitzer Prize winners & 50 & 712 & 810 & $0.88(0.51-1.51)$ \\
\hline
\end{tabular}

${ }^{*} p<0.05,{ }^{+} p<0.01$ 
Table 3: Coverage versus interest: article mentions of age-matched and page views-matched women and men in selected categories (2004-2009).

\begin{tabular}{|c|c|c|c|c|c|c|c|}
\hline \multirow[t]{2}{*}{ Category } & \multirow[t]{2}{*}{ Subcategory } & \multirow[t]{2}{*}{$\begin{array}{r}\text { Number of } \\
\text { matched } \\
\text { pairs }\end{array}$} & \multicolumn{2}{|c|}{$\begin{array}{c}\text { Interest: median } \\
\text { number of } \\
\text { Wikipedia page } \\
\text { views per month }\end{array}$} & \multicolumn{2}{|c|}{$\begin{array}{c}\text { Coverage: } \\
\text { median number of } \\
\text { newspaper } \\
\text { mentions per year }\end{array}$} & \multirow[t]{2}{*}{$\begin{array}{l}\text { Relative coverage } \\
\text { (women vs. men)/ } \\
\text { relative interest (women } \\
\text { vs. men) and bootstrap } \\
\text { tests of difference }(95 \% \\
\text { confidence intervals) }\end{array}$} \\
\hline & & & Women & Men & Women & Men & \\
\hline All categories & All names & 10,420 & 1,074 & 1,075 & 300 & 826 & $0.36(0.34 ; 0.38)^{\dagger}$ \\
\hline \multirow{11}{*}{$\begin{array}{l}\text { Entertainment } \\
\text { (U.S.) }\end{array}$} & All entertainers & 5,826 & 2,478 & 2,476 & 261 & 513 & $0.51(0.48-0.55)^{\dagger}$ \\
\hline & Film actors & 3,766 & 3,508 & 3,511 & 296 & 494 & $0.60(0.55-0.65)^{\dagger}$ \\
\hline & TV actors & 3,745 & 3,347 & 3,299 & 283 & 454 & $0.61(0.57-0.69)^{\dagger}$ \\
\hline & Film directors & 229 & 1,287 & 1,288 & 664 & 870 & $0.76(0.56-1.12)$ \\
\hline & Singers & 1,024 & 1,626 & 1,604 & 336 & 558 & $0.59(0.51-0.73)^{\dagger}$ \\
\hline & Pop singers & 162 & 5,803 & 5,535 & 1,198 & 1,305 & $0.88(0.65-1.46)$ \\
\hline & Dancers & 107 & 1,510 & 1,548 & 462 & 535 & $0.89(0.54-1.33)$ \\
\hline & Television personalities & 294 & 2,269 & 2,341 & 523 & 862 & $0.63(0.49-0.90)^{\dagger}$ \\
\hline & Radio personalities & 85 & 1,135 & 1,143 & 238 & 480 & $0.50(0.27-1.06)$ \\
\hline & Oscar nominees & 162 & 28,611 & 28,626 & 13,699 & 12,883 & $1.06(0.85-1.47)$ \\
\hline & Emmy nominees & 100 & 17,587 & 18,510 & $5,470.5$ & 6,699 & $0.86(0.57-1.09)$ \\
\hline \multirow[t]{8}{*}{ Politics (U.S.) } & All politicians & 780 & 271 & 274 & 592 & 1,019 & $0.59(0.47-0.70)^{\dagger}$ \\
\hline & Governors & 22 & 1,894 & 1,895 & 7,656 & 20,508 & $0.37(0.23-1.82)$ \\
\hline & Mayors & 101 & 231 & 235 & 709 & 762 & $0.95(0.62-1.69)$ \\
\hline & Cabinet secretaries & 12 & 4,436 & 4,482 & 8,491 & 20,304 & $0.42(0.15-1.22)$ \\
\hline & Presidential candidates & 28 & 1,212 & 1,179 & 1,943 & 4,061 & $0.47(0.16-1.53)$ \\
\hline & Judges & 109 & 146 & 151 & 662 & 273 & $2.52(1.56-3.31)^{\dagger}$ \\
\hline & House representatives & 134 & 1,353 & 1,363 & 5,262 & 10,230 & $0.52(0.39-0.66)^{\dagger}$ \\
\hline & Senators & 25 & 7,014 & 7,353 & 38,306 & 52,880 & $0.76(0.42-1.77)$ \\
\hline \multirow[t]{5}{*}{ Business (U.S.) } & All businesspeople & 229 & 976 & 952 & 640 & 890 & $0.70(0.50-0.99)^{*}$ \\
\hline & Chief executives & 71 & 560 & 553 & 870 & 613 & $1.40(0.67-2.25)$ \\
\hline & Business executives & 13 & 991 & 952 & 800 & 855 & $0.90(0.05-3.51)$ \\
\hline & Company founders & 12 & 1,160 & 1,126 & 1,495 & 3,169 & $0.46(0.06-12.23)$ \\
\hline & Billionaires & 24 & 2,218 & 2,231 & 1,012 & 1,143 & $0.89(0.24-1.54)$ \\
\hline \multirow[t]{6}{*}{ Sports } & All athletes & 1,010 & 227 & 226 & 1,418 & 1,569 & $0.90(0.76-1.05)$ \\
\hline & $\begin{array}{l}\text { Tennis Grand Slam } \\
\text { champions (all nations) }\end{array}$ & 29 & 4,325 & 4,388 & 9,828 & 4,036 & $2.47(0.85-4.88)$ \\
\hline & Soccer players (U.S.) & 55 & 453 & 458 & 1,233 & 1,363 & $0.91(0.34-1.44)$ \\
\hline & Basketball players (U.S.) & 289 & 271 & 269 & 3,131 & 692 & $4.49(2.97-6.18)^{\dagger}$ \\
\hline & Golf players (U.S.) & 268 & 138 & 138 & 1,014 & 1,647 & $0.62(0.44-0.81)^{\dagger}$ \\
\hline & Olympic athletes (U.S.) & 127 & 370 & 370 & 2,275 & 1,863 & $1.22(0.72-1.57)$ \\
\hline \multirow[t]{6}{*}{ Arts and literature } & All artists and writers & 1,342 & 372 & 373 & 217 & 352 & $0.62(0.52-0.72)^{\dagger}$ \\
\hline & Painters & 148 & 186 & 186 & 64 & 107 & $0.60(0.30-1.01)$ \\
\hline & Photographers & 184 & 333 & 329 & 138 & 223 & $0.61(0.40-0.84)^{\dagger}$ \\
\hline & Sculptors & 51 & 140 & 140 & 83 & 116 & $0.71(0.33-1.76)$ \\
\hline & Writers & 815 & 480 & 486 & 281 & 499 & $0.57(0.47-0.72)^{\dagger}$ \\
\hline & Pulitzer Prize winners & 35 & 757 & 723 & 1,218 & 1,356 & $0.86(0.46-2.64)$ \\
\hline
\end{tabular}

\footnotetext{
${ }^{*} p<0.05,{ }^{\dagger} p<0.01$
}

$(n=826)$ was nearly three times higher than the median number of mentions for women $(n=300)$, with the difference highly significant $(p<0.01)$. We also found a substantial and significant difference (at least 1.5 times greater coverage volume for 


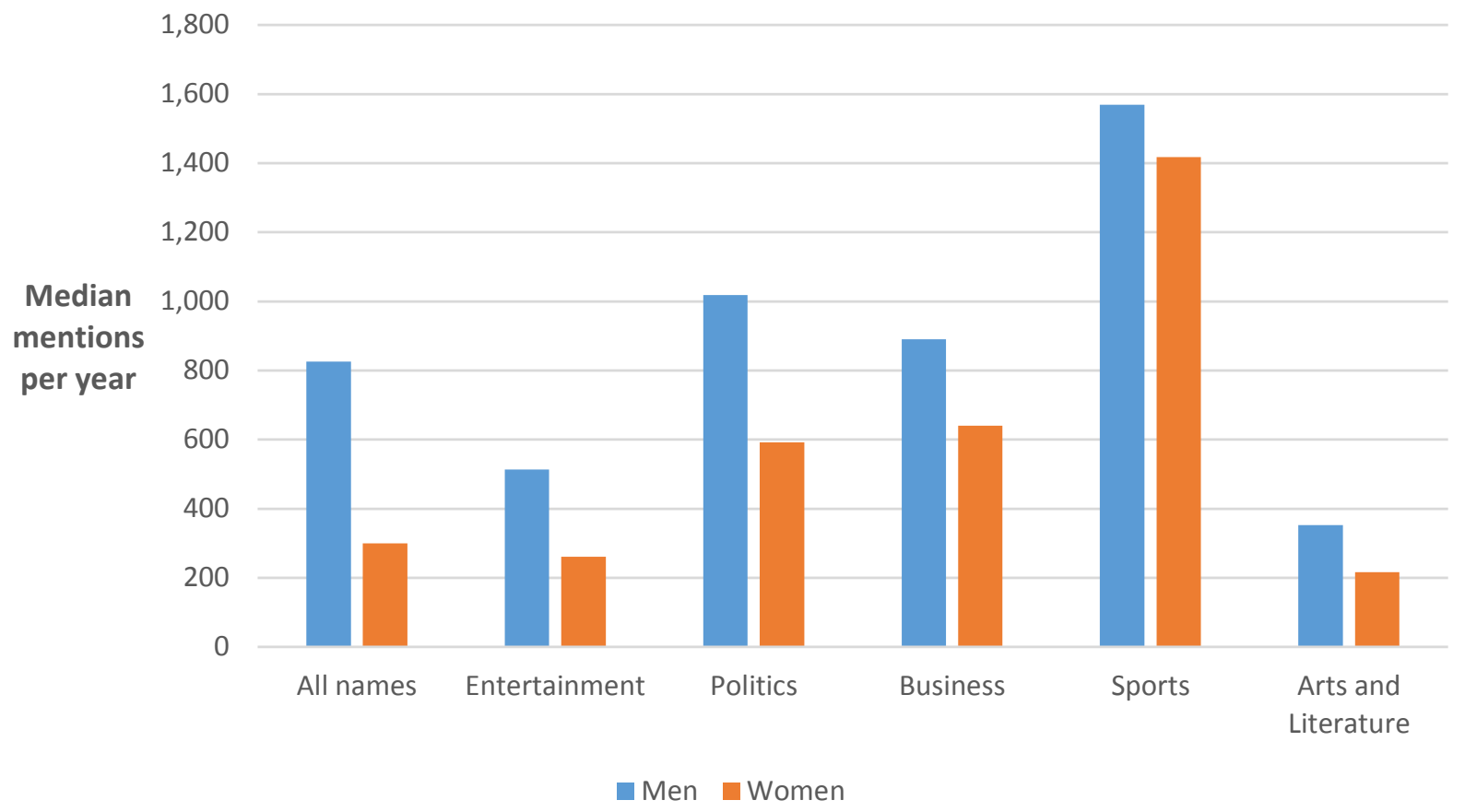

Figure 1: Median number of newspaper mentions per year for men and women who were matched on occupation, public interest, and age.

men) in most of the specific domains, including politics, business, entertainment, and arts and literature.

When examining more specific subdomains, Table 3 shows a large and statistically significant coverage volume advantage for men in most of the entertainment subfields. Men also received a greater coverage volume in most categories of business and politics, although the difference was often nonsignificant because of small sample sizes. The category of business is especially interesting, as it clearly demonstrates the importance of accounting for public interest. In Table 1, where we did not account for this factor, women appeared to receive greater coverage than similarly positioned men in subdomains such as business chief executives and company founders. However, the results in Table 3 show that once we matched on public interest, which was much higher for successful businesswomen, this ostensible female coverage advantage vanished.

Another category where accounting for public interest proved to be crucial was sports. Table 3 shows that after pairing on public interest, the coverage for female tennis Grand Slam champions and for American basketball players-two domains where men enjoy much higher public interest-was substantially higher than the coverage for matched males in each of these domains. The difference for basketball players was especially large (a coverage disparity of nearly 4.5:1 in favor of women) and clearly significant. These results stand in contrast to those reported in Table 1, where men enjoyed a clear coverage advantage, highlighting the importance of considering public interest when comparing coverage patterns. 


\section{Conclusion and Discussion}

In this study, we reassessed prior claims about gender bias in newspapers using a novel methodological approach. We compared media coverage (measured by name mentions) and public interest (measured through Internet activity) for more than 20,000 notable men and women in various social and occupational domains. Our study is the first to tackle the longstanding question of gender bias in media coverage while accounting not only for gender inequalities in structural positions and achievements but also for public interest. We found that despite greater public interest in the typical woman, the typical man was mentioned more than twice as much. After matching men and women by age, by structural position, and by public interest, newspapers clearly awarded men with a substantially larger coverage volume in nearly all fields. Hence, even women who have reached important achievements and who clearly garner considerable public interest are habitually less likely to receive media attention than men who attract equal public interest.

Our study offers an important contribution not only to the mass communication literature on gendered media coverage differentials but also to the larger literature on cultural and occupational gender inequalities. Our findings demonstrate that theoretical propositions highlighting either structural inequalities or individual differences in motivation, effort, talent, or charisma are insufficient when trying to account for the gendered coverage gap. First, the research on gender inequalities in the job market has highlighted barriers for women both in entering professions and advancing within these professions (Cotter et al. 2001; England 2005, 2010; Morgan 1998; Reskin 2003), contributing to women's much lower presence in the public sphere, particularly in high-profile positions that tend to attract media attention. We previously suggested that these structural inequalities likely contribute considerably to the coverage gap, as this gap has somewhat narrowed with the growing entrance of women into the job market (Shor et al. 2015). Although such inequalities are indeed important, the present study demonstrates that they cannot fully explain the gap, which remains substantial even when comparing men and women who have reached similar positions and achievements.

Similarly, propositions that focus on personal characteristics, motivations, and choices are also insufficient in accounting for the coverage gap. The literature on gender inequalities suggests that women may be considered less worthy of public attention. This is both because of cultural beliefs that devalue women and their actions (Ridgeway 2009, 2011, 2013) and because women suffer from shorter career durations in prominent offices (Cook and Glass 2013; Ryan and Haslam 2005), are assigned less important and salient positions (Kanter 1977; Madden 2012; Smith 2002), and are less likely to be self-promoting (Castagnetti and Rosti 2013; Manning and Saidi 2010; Ridgeway et al. 2009). We argued that such differences, when they exist, should be, at least in part, manifested in reduced levels of public interest. That is, if successful women spend relatively less time in prominent positions and their actions are both devalued and less self-promoted, then we should expect the public to be less interested in them. However, we found that, in fact, most women who have reached leading positions and notable achievements in various social 
and occupational fields tend to attract greater public interest when compared with men who have reached similar success. This may be a result of the lower number of women in leading positions, making them unique and therefore arguably more newsworthy. It could also be that those women who did reach key positions and achievements, despite well-documented barriers, are on average more qualified, talented, or charismatic than their male equivalents and thus draw greater public attention.

To conclude, real-world structural inequalities and differential public interest appear to explain only about half of the full gender gap in coverage, which conservatively stands at about 4:1 in favor of men (Macharia 2015). But even when accounting for these factors, we found that successful women still receive less than half the coverage volume of equally successful men who attract similar public interest. Following the logic adopted by recent studies on gender pay gaps (Castagnetti and Rosti 2013; Dinovitzer et al. 2009), we suggest that at least part of this large remaining gap is likely due to media bias and discrimination. Unequal gender coverage appears to be deeply ingrained in daily media practices of reporting. It may result from deeply entrenched gendered status ideologies and cultural norms (Ridgeway 2011, 2013) and from what media scholars (e.g., Rodgers and Thorson 2003; Ross 2009; Ross and Carter 2011) have termed "the masculine culture of newsrooms."

But why is it that newspapers frequently seem to fail at meeting public interest? After all, journalistic aspirations to reach wider audiences, commercial considerations, and even concerns for social equity appear to suggest that a more balanced coverage, one that better caters to readers' interests, might benefit newspapers. We propose four possible explanations for this large discrepancy. First, it may be that newsmakers are not fully aware of what public interest actually looks like and that they hold certain misconceptions about the topics and individuals that garner greater interest. After all, newsmakers are not immune to prevailing cultural norms that see men and their actions as intrinsically more interesting and important (Ridgeway 2009, 2011, 2013), and they may consequently ignore evidence to the contrary. Second, commercial interests may not align with public interest. For example, if newspapers and advertisers primarily target certain groups of readers, such as wealthier audiences or audiences who are more likely to make decisions about large purchases (e.g., cars or houses), then they would be primarily interested in providing content about which these audiences would presumably like to read. Hence, if reporters and editors believe (whether rightfully or not) that their primary target audiences would like to read more about successful men than about successful women, then they will write about the former regardless of what the larger public is interested in. They may additionally cater to commercial interest by publishing paid content that features wealthy individuals, who are more likely male. Third, media-related inequalities may result from newsmakers failing to correct for men enjoying better access to reporters or being more responsive to their requests. And finally, editor and journalistic inclinations toward male coverage may stem from biases among agenda setters upstream, such as news agencies and tweeting presidents. 


\section{Notes}

1 See a discussion of the Wikipedia page views below.

2 The median monthly number of Wikipedia page views is a relatively straightforward measure of public interest. Other potential measures, such as article length or the mere number of articles in Wikipedia may be a function of those who commonly write and edit Wikipedia pages-predominantly men.

3 Paired $t$ tests and Wilcoxon signed rank tests produce very similar test results. We report results from bootstrap tests as distributions of coverage and interest vary wildly across categories, frequently violating distributional assumptions of other tests. The reported confidence intervals are obtained from nonparametric bootstrapping of the paired sample. The $p$ values are obtained from the permutation test in which within-pair genders are swapped randomly to create the resampling distribution.

4 Moreover, in some categories (e.g., Oscar nominees, governors, senators, billionaires, or tennis Grand Slam champions) we analyze the full population rather than just a sample. For these analyses, any difference in coverage, whether statistically significant or not, is meaningful.

\section{References}

Atkeson, Lonna Rae, and Timothy B. Krebs. 2008. "Press Coverage of Mayoral Candidates: The Role of Gender in News Reporting and Campaign Issue." Political Research Quarterly 61:239-52. https://doi.org/10.1177/1065912907308098

Bautin, Mikhail, Charles Ward, Akshay Patil, and Steven Skiena. 2010. "Access: News and Blog Analysis for the Social Sciences." Paper presented at the 19th International World Wide Web Conference, April 26-30, Raleigh, NC. Retrieved May 12, 2015 (https://dl.acm.org/citation.cfm?id=1772889). https://doi.org/10.1145/1772690. 1772889

Budig, Michelle J., and Paula England. 2001. "The Wage Penalty for Motherhood." American Sociological Review 66:204-25. https ://doi .org/10.2307/2657415

Castagnetti, Carolina, and Luisa Rosti. 2013. "Unfair Tournaments: Gender Stereotyping and Wage Discrimination among Italian Graduates." Gender \& Society 27:630-58. https : //doi.org/10.1177/0891243213490231

Cook, Alison, and Christy Glass. 2013. "Glass Cliffs and Organizational Saviors: Barriers to Minority Leadership in Work Organizations?" Social Problems 60:168-87. https: //doi.org/10.1177/0891243213490231

Cooky, Cheryl, Michael A. Messner, and Robin H. Hextrum. 2013. "Women Play Sport, but Not on TV: A Longitudinal Study of Televised News Media." Communication E Sport 1:203-30. https://doi.org/10.1177/2167479513476947

Correll, Shelley J. 2004. "Constraints into Preferences: Gender, Status and Emerging Career Aspirations." American Sociolgical Review 69:93-113. https://doi.org/10.1177/ 000312240406900106

Cotter, David A., Joan M. Hermsen, Seth Ovadia, and Reeve Vanneman. 2001. "The Glass Ceiling Effect." Social Forces 80:655-81. https://doi .org/10.1353/sof .2001.0091

Davis, Junetta. 1982. "Sexist Bias in Eight Newspapers." Journalism Quarterly 59:456-60. https://doi.org/10.1177/107769908205900316 
De Swert, Knut, and Marc Hooghe. 2010. "When Do Women Get a Voice? Explaining the Presence of Female News Sources in Belgian News Broadcasts (2003-5)." European Journal of Communication 25:69-84. https://doi .org/10.1177/0267323109354229

Dinovitzer, Ronit, Nancy Reichman, and Joyce Sterling. 2009. "The Differential Valuation of Women's Work: A New Look at the Gender Gap in Lawyers' Incomes." Social Forces 88:819-64. https://doi.org/10.1353/sof.0.0260

Eastman, Susan Tyler, and Andrew C. Billings. 2000. "Sportscasting and Sports Reporting: The Power of Gender Bias." Journal of Sport E Social Issues 24:192-213. https : //doi .org/ 10.1177/0193723500242006

England, Paula. 1992. Comparable Worth: Theories and Evidence. New York, NY: Aldine de Gruyter.

England, Paula. 2005. "Gender Inequality in Labor Markets: The Role of Motherhood and Segregation." Social Politics 12:264-88. https://doi.org/10.1093/sp/jxi014

England, Paula. 2010. "The Gender Revolution: Uneven and Stalled." Gender and Society 24:149-66. https://doi.org/10.1177/0891243210361475

England, Paula, and Su Li. 2006. "Desegregation Stalled: The Changing Gender Composition of College Majors, 1971-2002." Gender and Society 20:657-77. https : //doi . org/10 . 1177/ 0891243206290753

Falk, Erika. 2010. Women for President: Media Bias in Nine Campaigns. Champaign, IL: University of Illinois Press.

Fernandez, Roberto M., and M. Lourdes Sosa. 2005. "Gendering the Job: Networks and Recruitment at a Call Center." American Journal of Sociology 111:859-904. https://doi . org/10.1086/497257

Fiske, Susan. 2011. Envy up, Scorn Down: How Status Divides Us. New York, NY: Russell Sage Foundation.

Folke, Olle, and Johanna Rickne. 2016. "The Glass Ceiling in Politics: Formalization and Empirical Tests." Comparative Political Studies 49:567-99. https://doi .org/10.1177/ 0010414015621073

Fox, Richard L., and Jennifer L. Lawless. 2014. "Uncovering the Origins of the Gender Gap in Political Ambition." American Political Science Review 108:499-519. https: //doi .org/ $10.1017 / \mathrm{s} 0003055414000227$

Gallagher, Margaret. 2010. "Global Media Monitoring Project (GMMP) 2010." World Association of Christian Communictaion. http:/ /cdn.agilitycms.com/who-makes-thenews/Imported/reports_2010/global/gmmp_global_report_en.pdf.

Gans, Herbert J. 1979. Deciding What's News: A Study of CBS Evening News, NBC Nightly News, Newsweek, and Time. New York, NY: Vintage Books.

Glass, Jennifer, and Valerie Camarigg. 1992. "Gender, Parenthood, and Job-Family Compatibility." American Journal of Sociology 98:131-51. https://doi .org/10.1086/229971

Heldman, Caroline, Susan J. Carroll, and Stephanie Olson. 2005. "'She Brought Only a Skirt': Print Media Coverage of Elizabeth Dole's Bid for the Republican Presidential Nomination." Political Communication 22:315-35. https://doi.org/10.1080/ 10584600591006564

Hooghe, Marc, Laura Jacobs, and Ellen Claes. 2015. "Enduring Gender Bias in Reporting on Political Elite Positions: Media Coverage of Female MPs in Belgian News Broadcasts (2003-2011)." The International Journal of Press/Politics 20:395-414. https://doi . org/10. $1177 / 1940161215596730$ 
Jia, Sen, Thomas Lansdall-Welfare, Saatviga Sudhahar, Cynthia Carter, and Nello Cristianini. 2016. "Women Are Seen More Than Heard in Online Newspapers." PLOS One 11: e0148434. https://doi.org/10.1371/journal.pone.0148434

Kanter, Rosabeth M. 1977. Men and Women of the Corporation. New York, NY: Basic Books.

Kay, Fiona M., and John Hagan. 1995. "The Persistent Glass Ceiling: Gendered Inequalities in the Earnings of Lawyers." British Journal of Sociology 46:279-310. https : //doi .org/ $10.2307 / 591789$

Kay, Fiona M., and John Hagan. 1998. "Raising the Bar: The Gender Stratification of Law-Firm Capital." American Sociolgical Review 63:728-43. https://doi.org/10.2307/2657336

Khan, Walayet A., and Joāo Paolo Vieito. 2013. "CEO Gender and Firm Performance." Journal of Economics and Business 67:55-66. https://doi.org/10.1016/j.jeconbus.2013.01. 003

Lamont, Michèle. 2012. "Toward a Comparative Sociology of Valuation and Evaluation." Annual Review of Scoiology 38:201-21. https://doi.org/10.1146/ annurev-soc-070308-120022

Lavery, Lesley. 2013. "Gender Bias in the Media? An Examination of Local Television News Coverage of Male and Female House Candidates." Politics and Policy 41:877-910. https://doi.org/10.1111/polp.12051

Leicht, Kevin T. 2008. "Broken Down by Race and Gender? Sociological Explanation of New Sources of Earnings Inequality." Annual Review of Scoiology 34:237-55. https: //doi.org/10.1146/annurev.soc.34.040507.134627

Macharia, Sarah. 2015. "Global Media Monitoring Project 2015." World Association of Christian Communictaion. http://cdn.agilitycms.com/who-makes-thenews/Imported/reports_2015/global/gmmp_global_report_en.pdf.

Madden, Janice Fanning. 2012. "Performance-Support Bias and the Gender Pay Gap Among Stockbrokers." Gender and Society 26:488-518. https://doi.org/10.1177/ 0891243212438546

Manning, Alan, and Farzad Saidi. 2010. "Understanding the Gender Pay Gap: What's Competition Got to Do with It?" ILR Review 63:681-98. https://doi.org/10.1177/ 001979391006300407

Marx Feree, Myra, and Bandana Purkayastha. 2000. "Review: Equality and Cumulative Disadvantage: Reponse to Baxter and Wright." Gender and Society 14:809-13. https: //doi.org/10.1177/089124300014006007

McCombs, Maxwell E., and Donald L. Shaw. 1972. "The Agenda-Setting Function of Mass Media." Public Opinion Quarterly 36:176-87. https ://doi .org/10.1086/267990

Mills, Kay. 1997. "What Difference Do Women Journalist Make?" Pp. 41-55 in Women, Media and Politics, edited by P. Norris. Oxford, United Kingdom: Oxford University Press.

Morgan, Laurie A. 1998. "Glass-Ceiling Effect or Cohort Efect? A Longitudinal Study of the Gender Earnings Gap for Engineers, 1982 to 1989." American Sociolgical Review 63:479-83. https://doi.org/10.2307/2657263

Nghiem, Le T. P., Sarah K. Papworth, Felix K. S. Lim, and Luis R. Carrasco. 2016. "Analysis of the Capacity of Google Trends to Measure Interest in Conservation Topics and the Role of Online News." PLOS One 11:e0152802. https://doi.org/10.1371/journal .pone. 0152802

Reskin, Barabara. 2003. "Including Mechanisms in Our Models of Ascriptive Inequality: 2002 Presidential Address." American Sociolgical Review 68:1-21. https ://doi .org/10. $2307 / 3088900$ 
Reskin, Barabara F., and Denise D. Bielby. 2005. "A Sociological Perspective on Gender and Career Outcomes." Journal of Economic Perspectives 19:71-86. https://doi .org/10.1257/ 0895330053148010

Ridgeway, Cecilia L. 2009. "Framed Before We Know It: How Gender Shapes Social Relations." Gender and Society 23:145-60. https : //doi .org/10.1177/0891243208330313

Ridgeway, Cecilia L. 2011. Framed by Gender: How Gender Inequality Persists in the Modern World. Oxford, United Kingdom: Oxford University Press.

Ridgeway, Cecilia L. 2013. "Why Status Matters for Inequality." American Sociolgical Review 79:1-16. https://doi.org/10.1177/0003122413515997

Ridgeway, Cecilia L., Kristen Backor, Yan E. Li, Justine E. Tinkler, and Kristan G. Erickson. 2009. "How Easily Does a Social Difference Become a Status Distinction? Gender Matters." American Sociolgical Review 74:44-62. https://doi.org/10.1177/000312240907400103

Ridgeway, Cecilia L., and Shelley J. Correll. 2004. "Unpacking the Gender System: A Theoretical Perspective on Cultural Beliefs and Social Relations." Gender and Society 18:510-31. https://doi.org/10.1177/0891243204265269

Ripberger, Joseph T. 2011. "Capturing Curiosity: Using Internet Search Trends to Measure Public Attentiveness." Policy Studies Journal 39:239-59. https://doi.org/10.1111/j . $1541-0072.2011 .00406 . x$

Robertson, Terry, Allison Conley, Kamila Szymczynska, and Ansley Thompson. 2009. "Gender and the Media: An Investigation of Gender, Media, and Politics in the 2000 Election." New Jersey Journal of Communication 10:104-17. https ://doi .org/10.1080/ 15456870209367418

Rodgers, Shelly, and Esther Thorson. 2003. "A Socialization Perspective on Male and Female Reporting." Journal of Communication 53:658-75. https://doi .org/10.1111/j . 1460-2466.2003.tb02916.x

Ross, Karen. 2009. Gendered Media: Women, Men, and Identity Politics. Lanham, MD: Rowman and Littlefield Publishers.

Ross, Karen, and Cynthia Carter. 2011. "Women and News: A Long Winding Road." Media, Culture and Society 33:1148-65. https://doi .org/10.1177/0163443711418272

Ryan, Michelle K., and S. Alexander Haslam. 2005. "The Glass Cliff: Evidence That Women Are Over-Represented in Precarious Leadership Positions." British Journal of Management 16:81-90. https://doi.org/10.1111/j.1467-8551.2005.00433.x

Sanchez, Laura, and Elizabeth Thomson. 1997. "Becoming Mothers and Fathers: Parenthood, Gender, and the Division of Labor." Gender and Society 11:747-72. https ://doi .org/10. 1177/089124397011006003

Shor, Eran, Arnout van de Rijt, Charles Ward, Saoussan Asakar, and Steven Skiena. 2014a. "Is There a Political Bias? A Computational Analysis of Female Subjects' Coverage in Liberal and Conservative Newspapers." Social Science Quarterly 95:1213-29. https: //doi.org/10.1111/ssqu.12091

Shor, Eran, Arnout van de Rijt, Charles Ward, Aaron Blank, and Steven Skiena. 2014b. "Time Trends in Printed News Coverage of Female Subjects, 1880-2008." Journalism Studies 15:759-73. https://doi.org/10.1080/1461670x.2013.834149

Shor, Eran, Arnout van de Rijt, Alex Miltsov, Vivek Kulkarni, and Steven Skiena. 2015. "A Paper Ceiling: What Explains the Sex-Ratio Inequality in Printed News Coverage?" American Sociological Review 80:960-84. https://doi .org/10.1177/0003122415596999

Shor, Eran, Arnout van de Rijt, and Alex Miltsov. 2019. "Do Women in the Newsroom Make a Difference? Sentiment toward Women and Men as a Function of Newsroom Composition." Sex Roles 81:44-58. https://doi .org/10.1007/s11199-018-0975-8 
Skiena, Steven, and Charles Ward. 2013. Who's Bigger? Where Historical Figures Really Rank. Cambridge, United Kingdom: Cambridge University Press. https://doi .org/10.1017/ CB09781139649605

Smith, Kevin B. 1997. "When All's Fair: Signs of Parity in Media Coverage of Female Candidates." Political Communication 14:71-82. https://doi.org/10.1080/105846097199542

Smith, Ryan A. 2002. "Race, Gender, and Authority in the Workplace: Theory and Research." Annual Review of Scoiology 28:509-42. https ://doi .org/10.1146/annurev. soc . 28.110601 .141048

Solomon, David H., Eugine Soltes, and Denis Sosyura. 2014. "Winners in the Spotlight: Media Coverage of Fund Holdings as a Driver of Flows." Journal of Financial Economics 113:53-72. https://doi.org/10.1016/j.jfineco.2014.02.009

Sorensen, Alan T. 2007. "Bestseller Lists and Product Variety." The Journal of Industrial Economics 55:715-38. https://doi.org/10.1111/j.1467-6451.2007.00327.x

Tuchman, Gaye. 1979. "Women's Depiction by the Mass Media." Signs 4:528-42.

Van de Rijt, Arnout, Eran Shor, Charles Ward, and Steven Skiena. 2013. "Only 15 Minutes? The Social Stratification of Fame in Printed Media." American Sociological Review 78:26689.https://doi.org/10.1177/0003122413480362

Wasburn, Philo C., and Mara H. Wasburn. 2011. "Media Coverage of Women in Politics: The Curious Case of Sarah Palin." Media, Culture E Society 33:1027-41. https : //doi . org/10 . $1177 / 0163443711415744$

Weber, Andrea, and Christine Zulehner. 2010. "Female Hires and the Success of Start-up Firms." The American Economic Review 100:358-61. https://doi .org/10.1257/aer. 100. 2.358

Yoshida, Mitsou, Yuki Arase, Takaaki Tsunoda, and Mikio Tamamoto. 2015. "Wikipedia Page View Reflects Web Search Trend." Paper presented at the Proceedings of the ACM Web Science Conference, June 28-July 1, Oxford, United Kingdom. Retrieved June 14, 2017. http://dx.doi.org/10.1145/2786451.2786495

Eran Shor: Department of Sociology, McGill University. E-mail: eran.shor@mcgill.ca.

Arnout van de Rijt: Social and Behavioural Sciences, Utrecht University.

E-mail: arnoutvanderijt@gmail.com.

Babak Fotouhi: Program for Evolutionary Dynamics, Harvard University. E-mail: babak_fotouhi@fas.harvard.edu. 